\title{
Solid State Recycling of Recyclable Aluminum Wastes with In-Process Microstructure Control
}

\author{
Tatsuhiko Aizawa, Tachai Luangvaranunt* and Katsuyoshi Kondoh \\ Research Center for Advanced Science and Technology, The University of Tokyo, Tokyo 153-8904, Japan
}

\begin{abstract}
Aiming for actual dematerialization, mass flow must be optimized to make full use of the recyclable materials as input and to reduce total amount of wastes. Since the material efficiency is strongly dependent on their adaptivity to the design demand for recycled products, an effective recycling process must accompany the advanced materials processing and manufacturing to improve their original properties to the level above the demand. In the present paper, the light-mass non-ferrous metallic alloys such as aluminum alloys are targeted, to utilize their bulk wastes, which are often ejected from the electric parts or members, as an input material, and to aim for their reuse as an automotive part. Dense, high-strengthened aluminum alloy compact, or, green materials are handled in the present forming and manufacturing up to the final net-shape formation of products by sinter-forging. Selection of reused materials and in-process improvement of their properties are essential keys in this barrier-free processing. Possibility to replace the conventional processing with this barrier-free process lies in: (1) Reduction of in-process energy and mass consumption, (2) Flexibility to yield various kinds of products without any realignment of processes, and (3) Adaptive in-process material modification to design for products in practical use.
\end{abstract}

(Received October 19, 2001; Accepted December 5, 2001)

Keywords: solid state recycling, green state forming, bulk mechanical alloying, aluminum silicon alloy, iron contaminants, in-process microstructure control, low energy consumption

\section{Introduction}

Significant reduction of total mass requirement or dematerialization is a keyword to realize the sustainable human society. ${ }^{1)}$ Barrier free processing can be defined as an environmentally benign manufacturing and materials processing (EBM) toward this dematerialization. ${ }^{2}$ Its first feature lies in the wide material selection to use various types of recyclable wastes as its starting material. As shown in Fig. 1, there are three ways of recyclable material flow in an ideal barrierfree processing. In the first way, physically separated parts of own product is used repetitively as an input material for the barrier-free processing. In this way, contaminants are possible to coexist with main components in the starting materials, and, these materials are irregularly shaped after crushing the waste products and parts. In the second way, recyclable wastes from a product generated in the other industries are used with or without mixture of other waste materials. No wastes are generated in the linkage of mass flow by continuing this mass flow routine. At its end-points, technological efforts are necessary to minimize the amount of actually emitted wastes from the total system. Use of the green wastes generated in the process itself is the third way. Feedback routines must be equipped with the main mass flow in the inside of the barrier free processing. As easily imagined, these ideal features must be modified in order to create adequate material flow to each material system towards reduction of total material mass.

EBM must be at first morphology-free to accept arbitrarily shaped materials as input in order that the first and second ways in Fig. 1 should be realized. It must be also robust to contaminant enough to make processing of recyclable wastes straightforwardly from input. To save the intermediate wastes in the production line or to realize the third way, outputs emit-

${ }^{*}$ Graduate Student, The University of Tokyo.

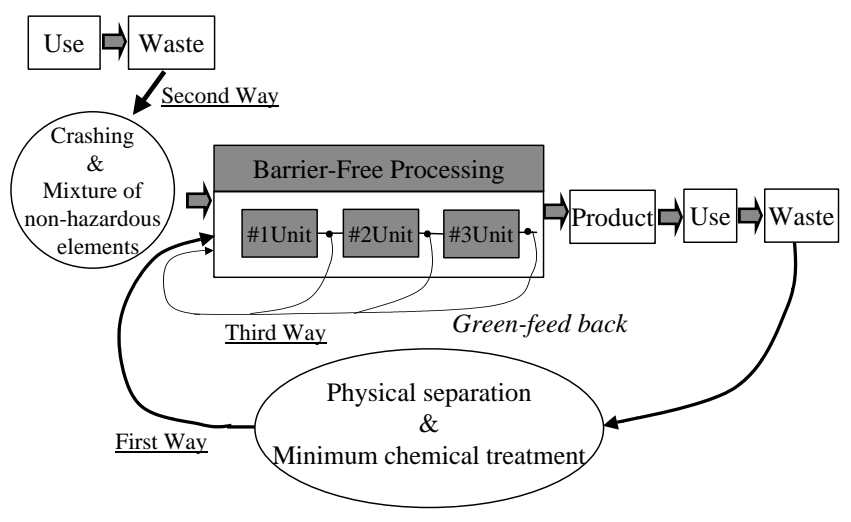

Fig. 1 Three ways of mass flow: Wide material selection in each production, Minimization of material emission by pipe-line connection and Inverse manufacturing in each production.

ted from the most of intermediate processes might well be recovered as an input material to EBM. This green materialization characterizes the first necessary feature for the greenstate forming.

In addition to wider material selection, output products via EBM must have proof of reliability. ${ }^{3)}$ As the first item, nearly the same functionality as a virgin material is required for outputs via EBM in order that the product made from the recycled materials should have the same industrial value as the virgin ones. Design adaptivity to use or reuse is the second item to completely satisfy the demanded service to the recycled materials. In-process enhancement of properties during EBM is also an important third item to prolong the life time of recycled products. Figure 2 summarizes the technological perspective including importance of these three items. No improvement of mechanical properties can be expected for the recycled materials via the conventional cascading-recycling, or, remelting and solidification. Since the solidified materials have coarse grains, additional thermo-mechanical processing 


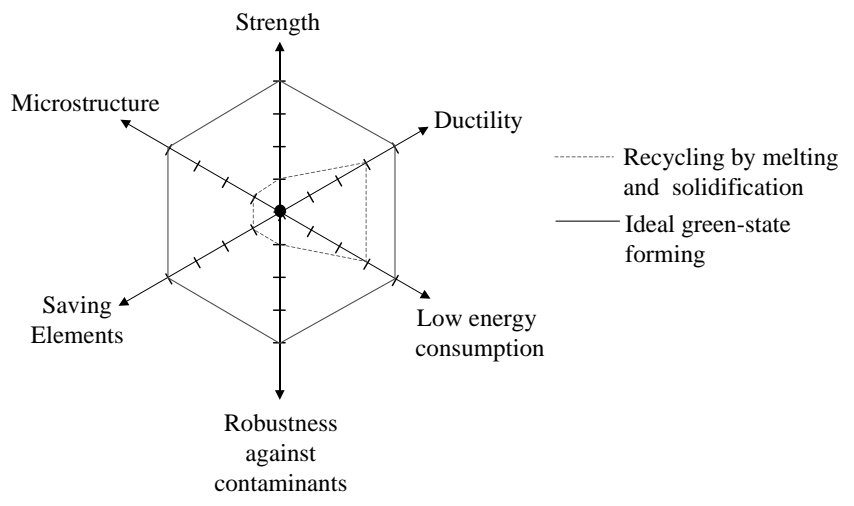

Fig. 2 Proof of reliability as an industrial material to be selected.

is necessary to make microstructure control. At the presence of contaminants or additives, relatively large amounts of slag or dross are ejected from the remelting process. In the ideal green state forming, microstructure control with grain size refinement takes place during processing. No additive elements are necessary for improvement of microstructure; e.g. silicon is positively utilized for precipitation hardening. Even contaminant elements are actively utilized for solid-solution strengthening. Reduction of energy consumption is an issue for this green state forming to replace the conventional processing.

In the present study, the solid state recycling process is proposed to realize the above system of the green-state forming. Aluminum-silicon alloy is employed to describe the general characteristics of this approach. Effect of in-process silicon particle size refinement on the mechanical properties is discussed together with the active use of iron contaminant to aluminum for precipitation strengthening of aluminum matrix. On the basis of the online monitored imposed energy, the energy consumption in the present processing is compared with that for the commercial mass-production. Through the above demonstrations, validity and effectiveness of the present processing is stressed as a promising EBM.

\section{Ideal System Towards Dematerialization of Alu- minum Alloys}

As reported in Ref. 4), total material requirement (TMR) for mining and smelting aluminum (TMR-Al) from an ore is $10.0 \mathrm{t} / \mathrm{metal}-\mathrm{t}$. That is, 10 ton rocks, soils or other matters must be shoveled out from the earth to yield 1 ton metal aluminum. With increasing the total amount of raw aluminum in use, TMR for production of aluminum or P-TMR-Al drastically increases: e.g. P-TMR-Al reaches $239.0 \mathrm{Mt} / \mathrm{y}$ for aluminum. Hence, in parallel to low-TMR material selection, total amount of materials in use must be reduced as low as possible in the ideal system towards dematerialization. Additive elements are also necessary to strengthen pure aluminum for industrial use. Even in this stage, any elements must be prohibited to use when they increase TMR or P-TMR. Table 1 shows a list of TMR and P-TMR for $\mathrm{Al}, \mathrm{Fe}$ and $\mathrm{Si}$. Use of low-TMR Fe and Si for strengthening is adaptive to dematerialization. In addition, the energy consumption for recycling must be also reduced as possible. In the cascade-type recycling, smelting and remelting of the aluminum rods re-
Table 1 List of TMR and P-TMR for aluminum, iron and silicon.

\begin{tabular}{cccccc}
\hline \multicolumn{2}{c}{ Al } & \multicolumn{2}{c}{ Fe } & \multicolumn{2}{c}{$\mathrm{Si}$} \\
\hline $\begin{array}{c}\text { TMR } \\
(\mathrm{t} / \mathrm{metal}-\mathrm{t})\end{array}$ & $\begin{array}{c}\text { P-TMR } \\
(\mathrm{Mt} / \mathrm{y})\end{array}$ & $\begin{array}{c}\text { TMR } \\
(\mathrm{t} / \mathrm{metal}-\mathrm{t})\end{array}$ & $\begin{array}{c}\text { P-TMR } \\
(\mathrm{Mt} / \mathrm{y})\end{array}$ & $\begin{array}{c}\text { TMR } \\
(\mathrm{t} / \mathrm{metal}-\mathrm{t})\end{array}$ & $\begin{array}{c}\text { P-TMR } \\
(\mathrm{Mt} / \mathrm{y})\end{array}$ \\
\hline 10.0 & 239.0 & 5.1 & 2912.1 & 4.5 & 15.3 \\
\hline
\end{tabular}

quires the highest energy consumption in the mass flow of aluminum. Hence, in order to increase the mass fraction of recyclable aluminum waste in the total mass flow, these aluminum wastes to be fed-back must be processed in the solid state.

Considering the three ways of mass flow in Fig. 1 in the recycling of aluminum in the solid state, every unit in manufacturing and materials processing might well handle the high dense compact or the green-state materials except for the input and output. Different from the solidified materials, the green compact has sufficient flowability to be net-shaped into various products. Other recyclable wastes can be also mixed or sometimes alloyed with the green compact as an additive for strengthening the original aluminum. As shown in Fig. 3, the crushed chips and granules, or, the remelt blocks and agglomerates with various sizes and shapes are accepted as an input material. Hence, as the first and the second ways of mass routine, any physically separated and crushed chips can be fed to this green-state forming as input. In nature, various contaminants or impurities are inevitably included into this input. In this system, these materials are subjected to be in-process refinement and microstructure-control so that the highly dense compact or the green compact should be obtained as an intermediate material. This compact is further near-net shaped by warm-pressing and warm powder forging before final sinter-forging or surface modification. Any intermediate material ejected from each process before output remains green-state so that it can be fed-back to the input of this processing.

\section{Solid State Recycling of Aluminum Alloy}

The developed solid state recycling process is a typical green-forming or environmentally benign manufacturing for aluminum alloys. Bulk mechanical alloying (BMA) process plays a main contribution to this solid state recycling as illustrated in Fig. 4. After mechanically crushing the recyclable waste parts and members and chemically cleansing them, ascrushed chips, as-separated platelets or agglomerates or granules can be accepted as a starting material to BMA. In other words, different from the conventional P/M (Powder Metallurgy) processes, no powders need to be prepared for forming and sintering to products.

As had been theoretically and experimentally demonstrated in Refs. 5-10), the above starting materials are subjected to severe plastic deformation and flow in the repetitive manner during BMA. As illustrated in the pass schedule in Fig. 4, the starting materials are compressed to high dense compact with the relative density of approximately $80 \%$ or more, and the cyclic load is applied to this dense compact with the relatively high density kept constant. This cyclic loading was scheduled by the automatic computer control to have two compression 


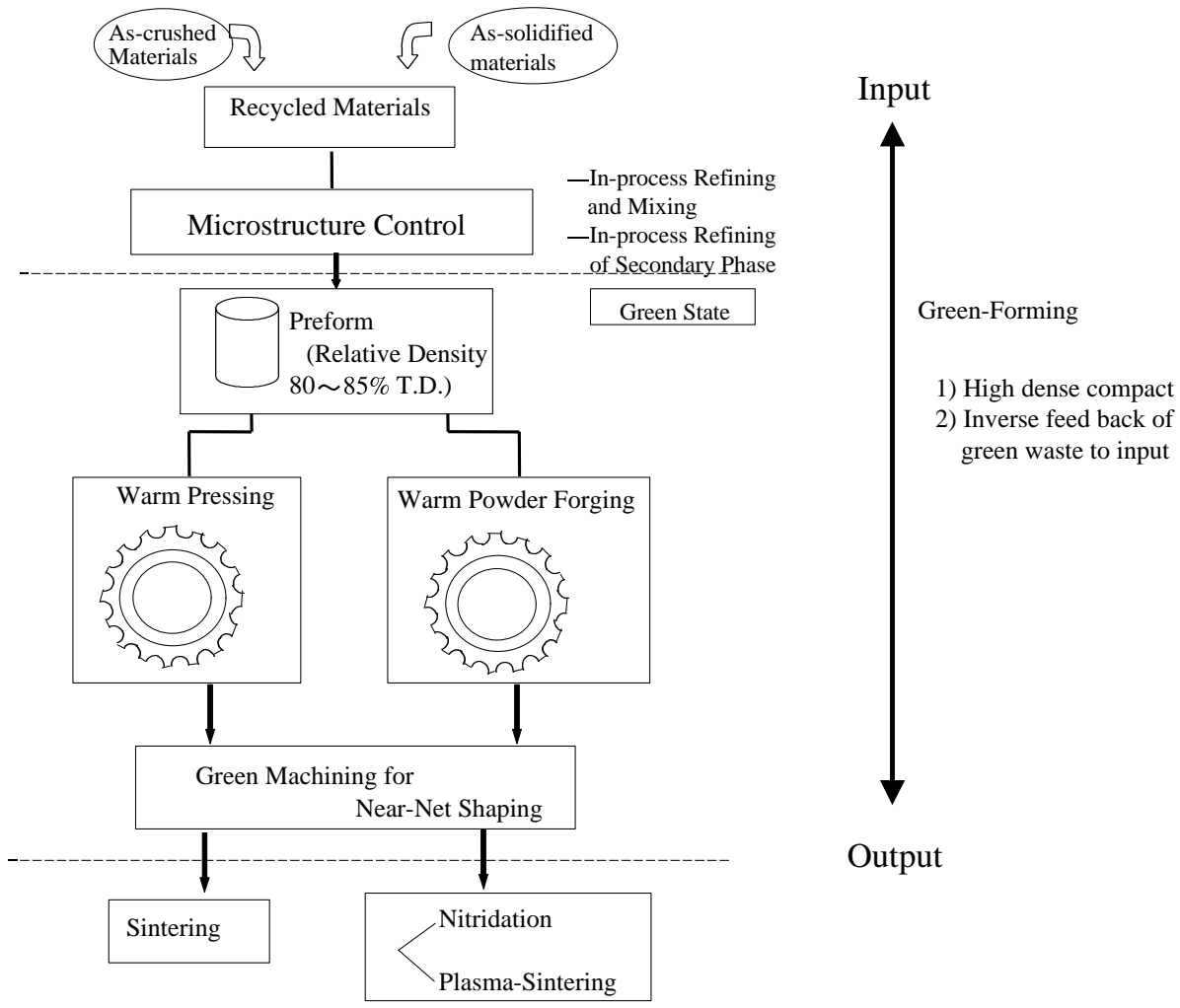

Fig. 3 Green-state forming as one of the most promising barrier-free processing for non-ferrous materials.

modes and one forward extrusion mode. In the first compression mode, the current density of processed compact is reset to have the prescribed relative density. Severe shear strains are applied to this dense sample in the forward extrusion mode. In this process, each constituent matter can be plastically deformed and sometimes fractured to fragments. In particular, the secondary phase embedded in the matrix can be easily broken into fine particles in the matrix. These deformed constituents and fragments are recombined to the original dense compact in the second compression mode. Although this cyclic process requires seven seconds per a cycle, every process automatically takes place at room temperature in the inert gas atmosphere only with increasing the number of cycles $(\mathrm{N})$.

In the present experiment, the mechanical chips were utilized as a model of recyclable waste and $\mathrm{Si}$ powders with the average diameter of $20 \mu \mathrm{m}$ was put into them in order to yield high Si-content aluminum alloys for automotive parts. Figure 5 shows mechanical chips machined from the solidified Al-12 mass\%Si alloy block. As observed in the SEM micrograph, the Si-particulate in a chip is large and irregularly shaped so that the original microstructure is inadequate as an industrial structural material. In order that this Si should play as a strengthening particulate, this microstructure must be modified in-process to house the uniformly distributing fine Si-particles. In parallel with the above homogenization and refinement of Si-particles, the yielded product must have sufficiently high density to be net-shaped to final product.

Figure 6 shows the solid-state recycled compact via bulk mechanical alloying with the relative density of about $80 \%$. Even when $N=400$, the silicon particle was reduced to under $5 \mu \mathrm{m}$ and these fine Si-particles distributed uniformly in the compact. Figure 7 depicts the forged Al-Si billet by using the sinter-upsetting. Full densification was attained at $T=673 \mathrm{~K}$ for $10 \mathrm{~min}$. No significant particle growth was seen in the SEM micrograph. Hence, the highly dense compact created via BMA can be easily net-shaped to lightweighed automotive parts by changing the final die-set.

\section{Case Studies for Discussion}

Effect of iron contaminants and Si-particle refinement on the in-process strengthening is discussed together with evaluation on the energy consumption in this processing.

\subsection{Effect of iron contaminants on the in-process strengthening}

Even after physical separation and chemical cleansing, the recyclable wastes have their own contaminants. In case of solid-state recycling of aluminum alloys, iron is thought to be a main contaminant: e.g. iron is inevitably included in a recycled aluminum alloy when recycling the aluminum-alloy pulltop with a steel can. While, as had been reported in Ref. 11), aluminum can be strengthened by formation of solid solution or intermetallic precipitates. Hence, if the solid solubility of iron into aluminum is enhanced or precipitates are in-process formed by using the bulk mechanical alloying, this contaminant can be utilized as a strengthening component in the solidstate recycling.

As a virgin material, this kind of Al-Fe alloys is attractive for strengthening the aluminum matrix, since it possesses high specific strength for typical aluminum alloys. The point to be noted is that there is very little solid solution between these two metals. Hence, Al-Fe alloys can be produced 


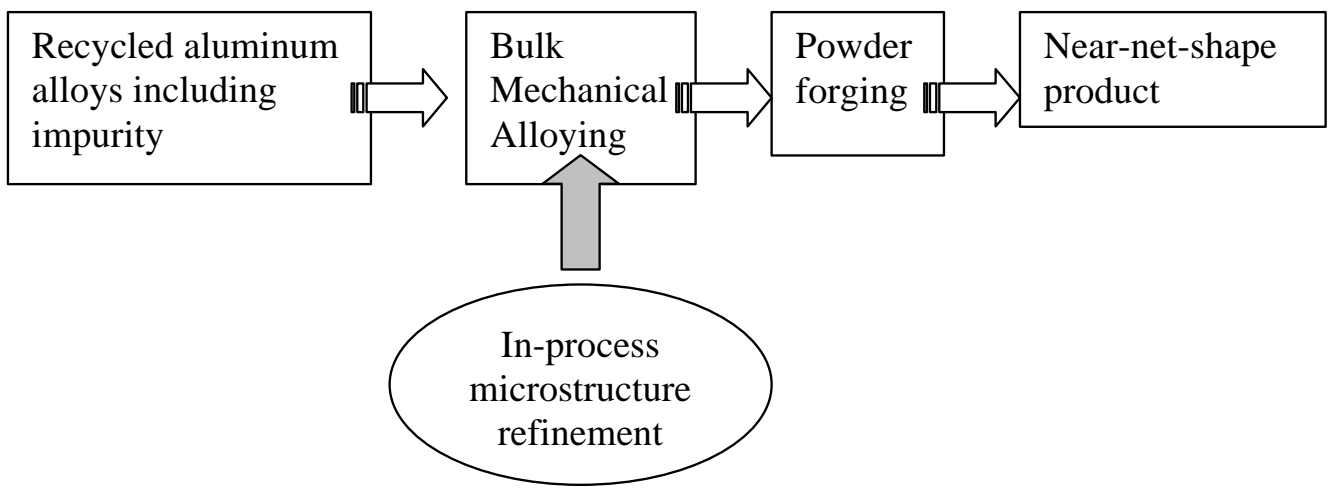

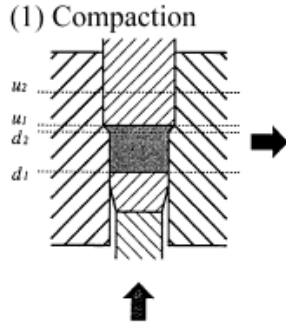

(6) Extrusion

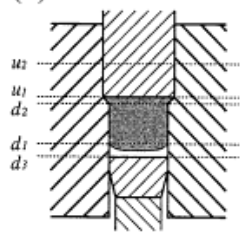

1

(5) Withdrawal

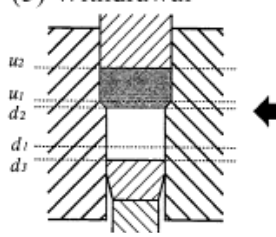

(2) Withdrawal

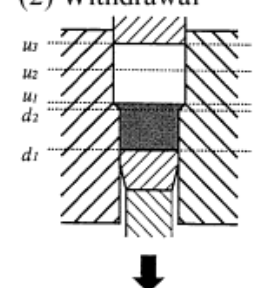

(3) Ejection

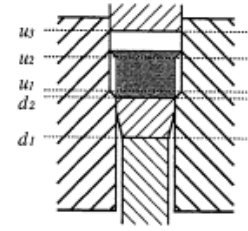

$\downarrow$

(4) Compaction

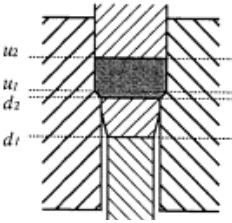

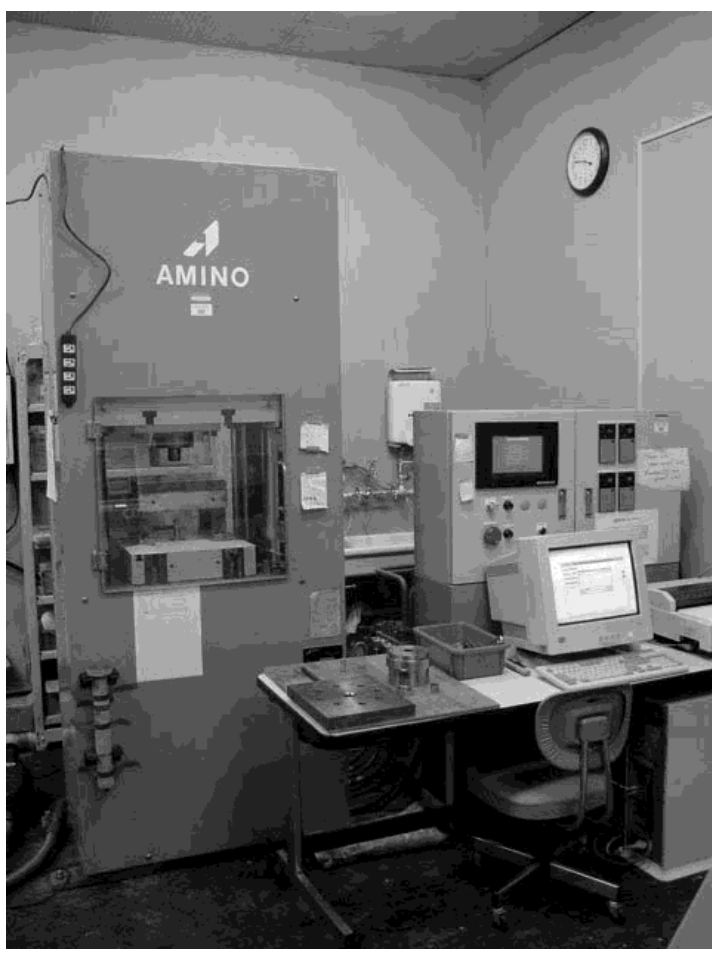

Fig. 4 Solid-state recycling process via bulk mechanical alloying for nonferrous materials.

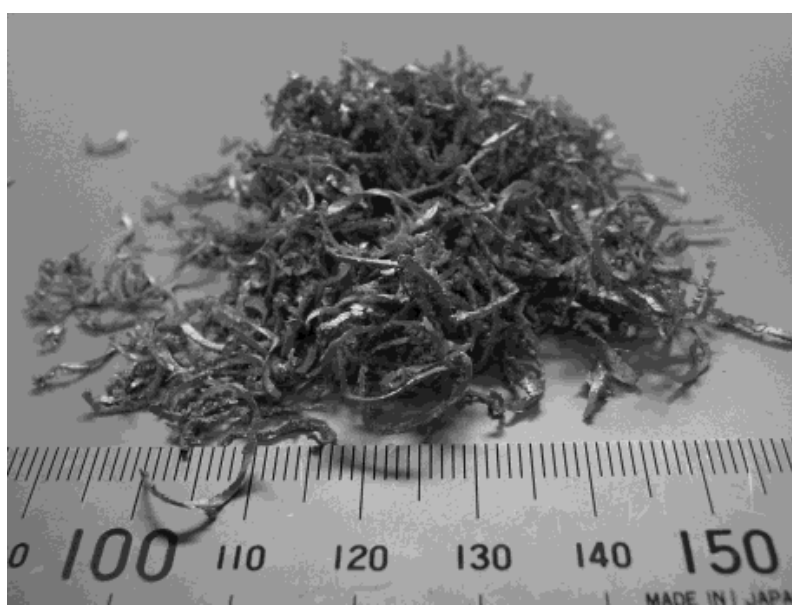

Fig. 5 Typical starting materials: mechanical chips of Al-Si blocks.

only in solid state by mechanical alloying (MA), ${ }^{11,13-16)}$ severe plastic deformation by torsion, ${ }^{17}$ ) and rapid solidifica- tion processing (RSP). ${ }^{12)}$ Microstructure of an Al-Fe alloy depends greatly on the atomic percent of $\mathrm{Fe}$, and the processing method. Various authors reported dissolution of Fe up to 4.5 atomic percent into FCC Al-matrix by both MA and RSP. Higher amount of $\mathrm{Fe}$ induces formation of amorphous phase. The alloy turns into a complete amorphous phase for Fe concentration higher than 25 percent. After heat treatment of the alloy, stable intermetallic compounds of $\mathrm{Al}$ and Fe are precipitated. ${ }^{14)}$ These precipitates are believed to contribute to the high temperature stability of the alloys. ${ }^{11)} \mathrm{Al}-\mathrm{Fe}$ alloys produced by RSP show a rapid coarsening of Al-Fe precipitates at high temperature; consequently resulting in the breakdown of strengthening mechanism of the alloy. ${ }^{11)}$ Mechanical alloying by ball milling/attrition can produce $\mathrm{Al}-\mathrm{Fe}$ alloy, but typical processing time is in the order of tens of hours. Ratio of ball to powder must be high enough for effective fragmentation and welding of the powder mixture to induce alloyment. This leads to the inefficiency and long processing time. After alloyment stage, the produced powder must be heat treated 


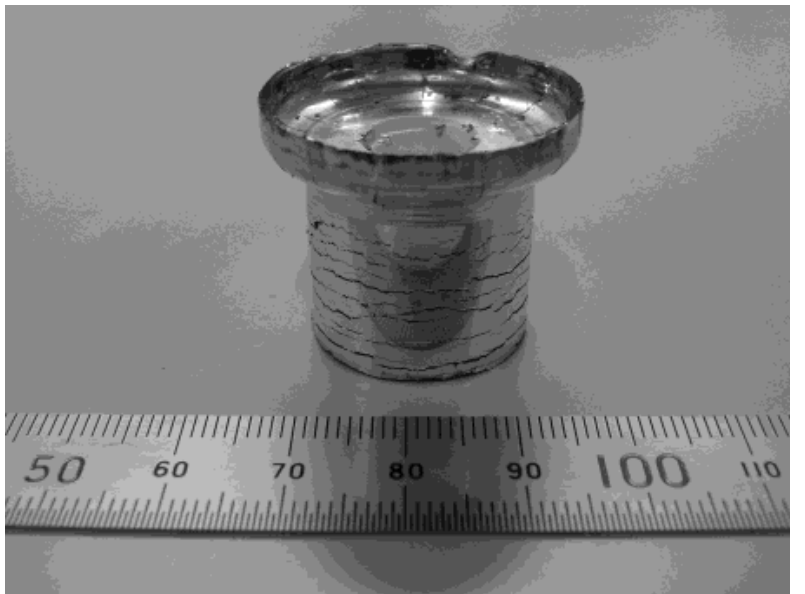

Fig. 6 High-dense powder compact with the relatively density over $80 \%$ T.D.

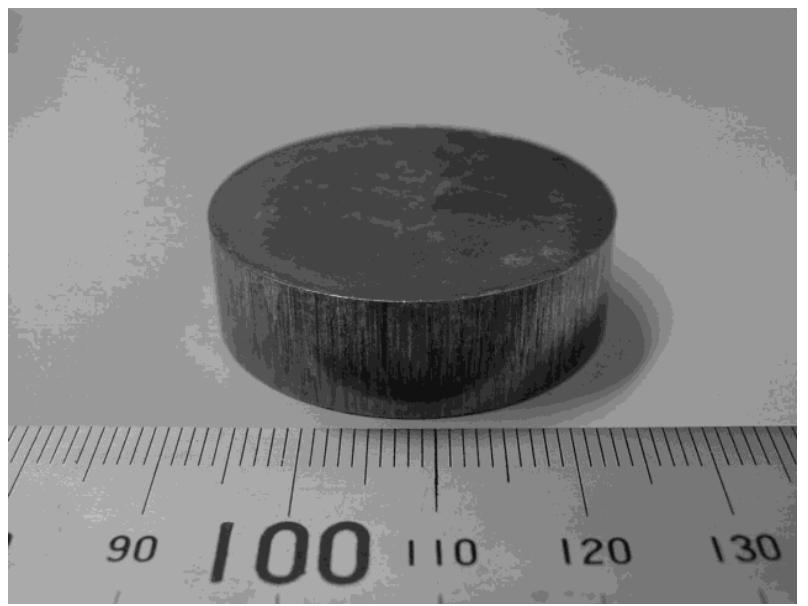

Fig. 7 Full-dense bullet sinter-forged from the high-dense powder compact.

to precipitate the intermetallics. In addition to demerits for practical processing, the above state-of-the-art technologies are never robust to iron contaminants to aluminum. This is mainly because (1) contaminants are always shaped irregular and relatively large-sized, (2) contaminants heterogeneously distribute in the recyclable waste, and (3) powders with intermetallic precipitates are too hard to make working.

In the bulk mechanical alloying, refinement with homogeneous mixing takes place to yield highly dense Al-Fe alloy compact from the contaminated aluminum block, chips or granules by iron or steel. In the following experiment, the powder mixture of pure atomized $\mathrm{Al}(33 \mu \mathrm{m}$ in mean size, $99.8 \%$ purity) and Fe ( $70 \mu \mathrm{m}$ in mean size, $99.5 \%$ purity) was employed as a model contaminated recyclable waste. Commercial die-wax type $\mathrm{L}$ of an amount equivalent to 0.2 mass $\%$ was mixed with the input material as a lubricant to reduce friction loss. The die was forced cool to keep the temperature under $333 \mathrm{~K}$ (or $60^{\circ} \mathrm{C}$ ). Highly dense, green compact after BMA was analyzed by optical microscopy and XRD. Vickers hardness was measured as a way to estimate the strength of the produced alloys.

Microstructure evolution for Al-4 mass \% Fe alloy after 200 and 400 BMA cycles is depicted in Fig. 8. Fe particles progressively dissolute into $\mathrm{Al}$ matrix, as BMA continues to higher number of cycles. The difference in atomic diameter of $\mathrm{Al}(0.28636 \mathrm{~nm})$ and $\mathrm{Fe}(0.24824 \mathrm{~nm})$ is $13 \%$. Hence, according to Hume-Rothery rule, solid solution can be formed but difficult. The observed disappearance of Fe in the matrix does not prove the solid solution formation of $\mathrm{Al}(\mathrm{Fe})$. In fact, XRD result in Fig. 9 shows precipitation of $\mathrm{Al}-\mathrm{Fe}$ intermetallics, specifically $\mathrm{Al}_{13} \mathrm{~F}_{4}, \mathrm{Al}_{5} \mathrm{Fe}$, and $\mathrm{AlFe}_{3}$ after $\mathrm{BMA}$ for 400 cycles. These intermetallic compounds are formed in situ, without the need of heat treatment. It is difficult to accurately see the peak shift of Fe or Al because of the overlapping between $\mathrm{Al}$ and $\mathrm{Fe}$ peaks. Then, the iron contaminating aluminum is thought to be partially changed to Fe-solute in the aluminum matrix and to be partially reacted into $\mathrm{Al}-\mathrm{Fe}$ intermetallic precipitates. The latter fine precipitates distributed homogeneously in the matrix, since no precipitate was seen in EPMA.

Vickers hardness of the Al-matrix indicates progressive hardening as shown in Fig. 10. The hardening of Al matrix is in general due to several factors, including work hardening, solid solution of $\mathrm{Fe}$ and precipitation of $\mathrm{Al}-\mathrm{Fe}$ intermetallics. Taking $\sigma_{\mathrm{y}}=H_{\mathrm{V}} / 3$, a rough estimate of the yield strength of $\mathrm{Al}-4$ mass $\% \mathrm{Fe}$ alloy produced after $400 \mathrm{BMA}$ cycles is $340 \mathrm{MPa}{ }^{11)}$ Since the yield of stress of pure aluminum is about $35 \mathrm{MPa}$, this strengthening is attributed not only to grain size refinement but also to precipitation hardening by the above $\mathrm{Fe}-\mathrm{Al}$ intermetallic compounds.

\subsection{Particle size refinement of $\mathrm{Si}$}

In the Al-Si alloy, particle size refinement of Si particles and their homogeneous distribution in the matrix must be a key to make in-process strengthening via BMA. As shown in Fig. 11(a), the initial Si particle size was 20 to $30 \mu \mathrm{m}$ in the mechanical chip. With increasing the number of cycles (N) in Fig. 11, Si particle size was reduced and the refined particles distribute in the matrix. As had reported in Ref. 9), reduction of the largest $\mathrm{Si}$ particle becomes important in the precipitation hardening. Figure 12 depicts the monotonic decrease of the largest Si particle size with increasing the number of cycles. Up to $N=100-200$, the Si particle size was significantly reduced while it gradually decreases with $N$ for $N>500$. This implies that the silicon particles are fractured with plastic flow of aluminum matrix by application of cyclic loading in BMA in the initial stage, and, that finer Si particles should only reduce their size reluctantly even with increasing $N$ for $N>500$.

\subsection{Energy consumption of the solid-state recycling}

Different from the conventional P/M-route processes, the mechanically imposed energy can be calculated and on-line monitored to the personal computer through the process computer. Figure 13 shows a typical variation of imposed energy per a cycle with increasing the number of cycles. At the pointed positions by arrows in Fig. 13, additional liquid wax was added to the processed samples to reduce the frictional work loss. Hence, the up-down variation of the imposed energy comes from the exaggerated frictional loss with increasing the number of cycles. Subtotal of imposed energy without the above friction loss was estimated to be $11.0 \mathrm{~kJ} /$ cycle. Applying the same pass schedule as shown in Fig. 4 to BMA without samples, the monitored energy provided us the con- 


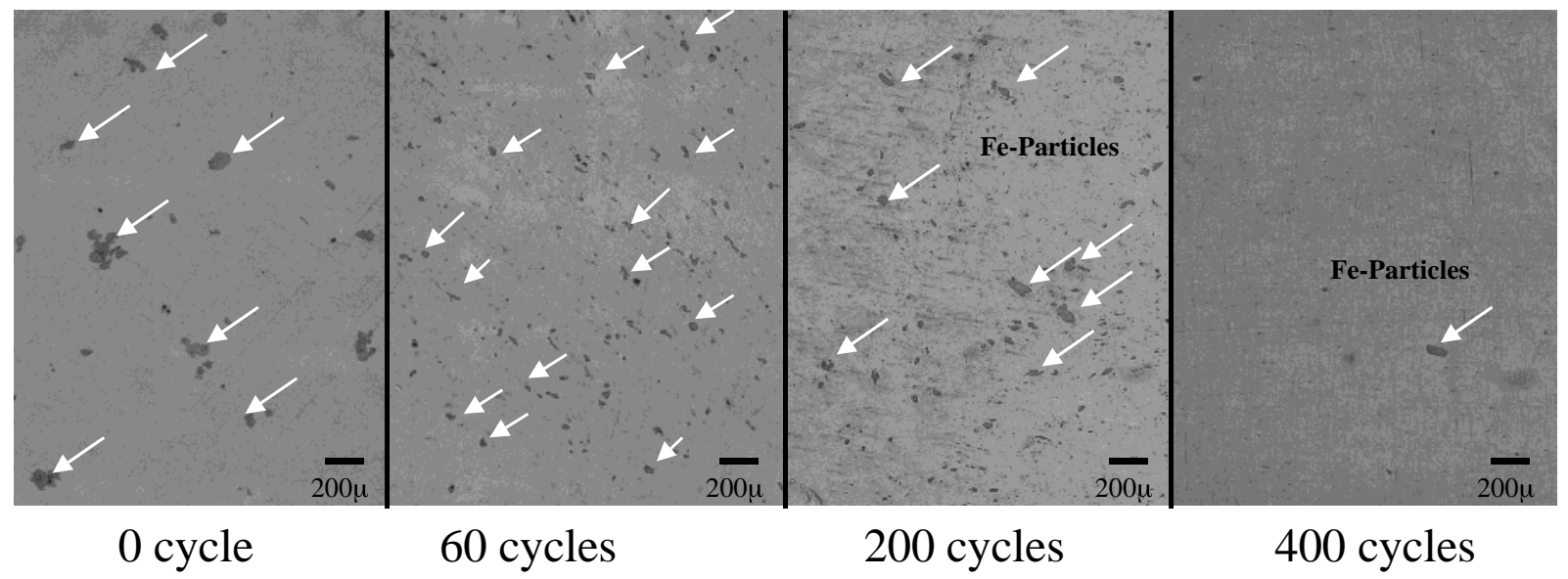

Fig. 8 Refinement of iron contaminant via bulk mechanical alloying.

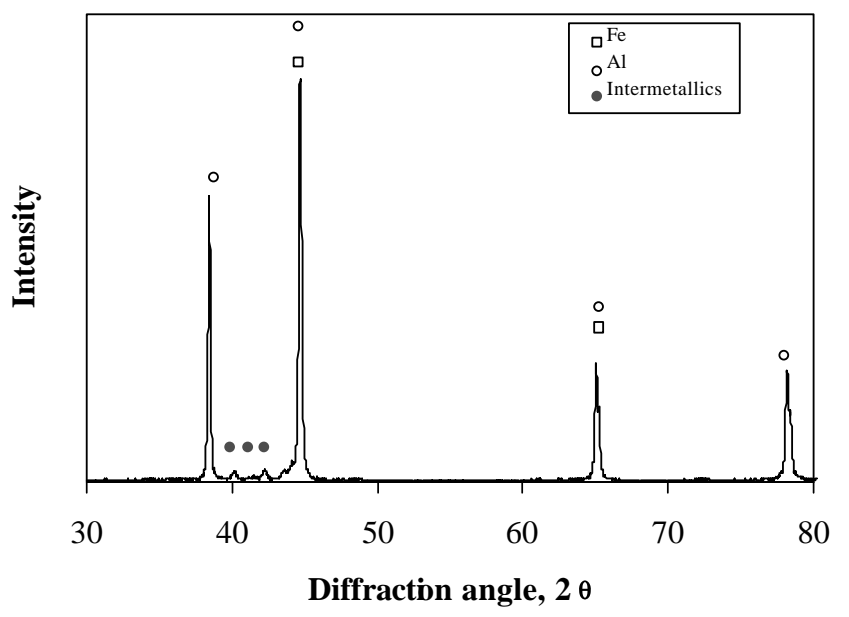

Fig. 9 XRD profiles of the processed high dense sample with Fe contaminants after 400 cycles in BMA.

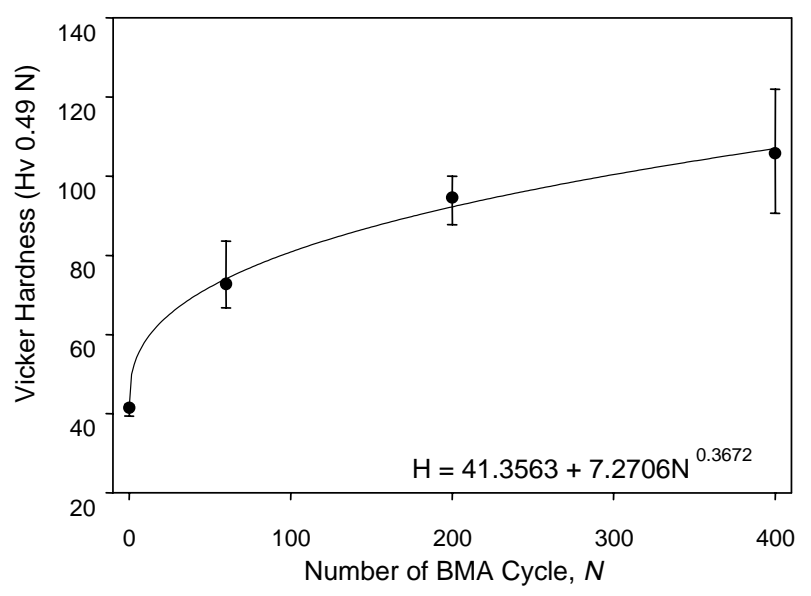

Fig. 10 Monotonic strengthening of aluminum compact with iron contaminants with increasing the number of cycles.

tribution of rigid motion to the imposed energy. Through the heat transfer analysis, the heat loss can be estimated in large. Table 2 lists each category of energy consumption and estimated energy. Only $45 \%$ of total energy is used for plastic work to sample materials in the present processing.

Assuming that the targeting largest $\mathrm{Si}$-particle size is $5 \mu \mathrm{m}$, the necessary number of cycles is 200 . Since a sample with

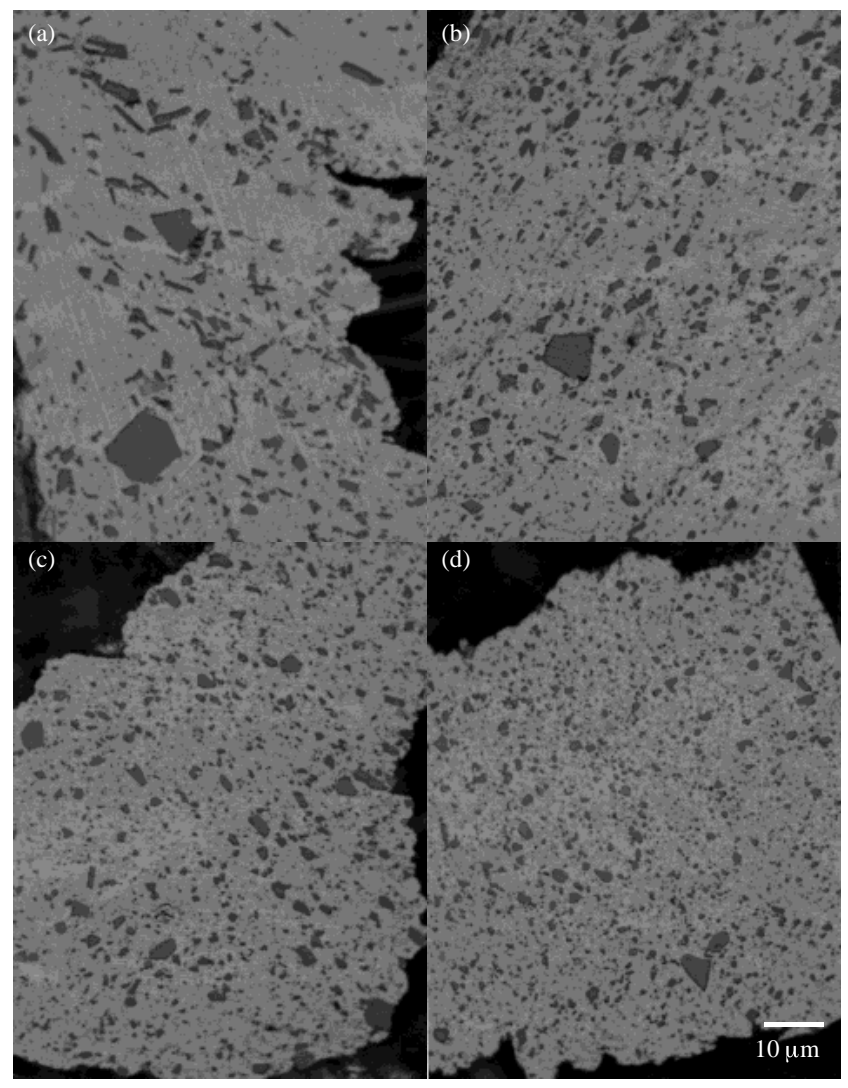

Fig. 11 Variation of microstructure for the in-processed Al-Si alloy with increasing the number of cycles: (a) as-received mechanical chip, (b) BMA 100 cycles, (c) 200 cycles, and (d) 500 cycles. Si-particulate was gradually refined in the aluminum matrix with increasing $\mathrm{N}$.

$20 \mathrm{~g}$ can be processed in the present BMA system, the total plastic work becomes $59 \mathrm{~kJ} / \mathrm{g}$. This value is comparable to the total energy consumption in the commercial $\mathrm{P} / \mathrm{M}$ process from atomizing to presintering for dense compact. Hence, the present solid-state recycling has the same or higher potential to save the energy consumption as or than the commercial mass-production by reducing the energy losses. 


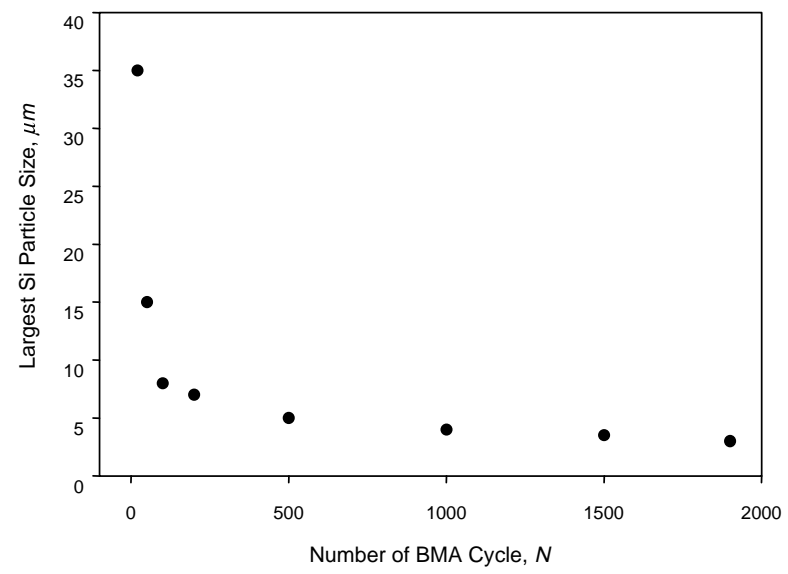

Fig. 12 Monotonic decrease of Si particle size with increasing the number of cycles.

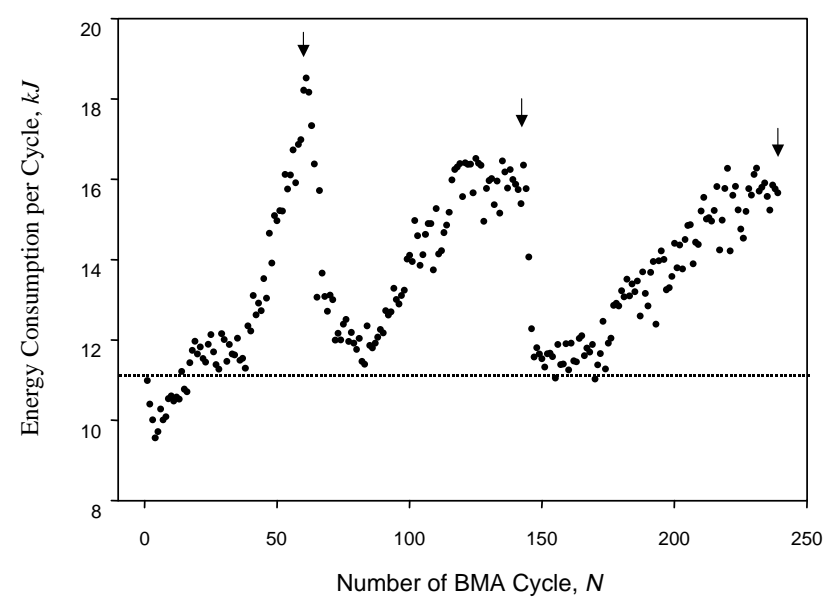

Fig. 13 Energy consumption per a cycle for $\mathrm{Al}-12 \% \mathrm{Si}$ alloys produced by bulk mechanical alloying.

Table 2 Categorization of energy consumption in the present solid-state recycling.

\begin{tabular}{lc}
\hline \multicolumn{1}{c}{ Category of energy } & $\begin{array}{c}\text { Amount of energy } \\
\text { per cycle }(\mathrm{kJ})\end{array}$ \\
\hline Plastic work to the material & 5.9 \\
Heat transfer from a sample & 0.6 \\
Rigid motion of die-set & 4.5 \\
Subtotal & $\mathbf{1 1 . 0}$ \\
Average friction loss to scuffing, die wear or noise & 2.3 \\
Total & $\mathbf{1 3 . 3}$ \\
\hline
\end{tabular}

\section{Conclusion}

The solid-state recycling has become an effective and powerful methodology to realize the green-state forming from the recyclable wastes to the automotive parts. Al-12\% Si alloy, highly dense compact with refined grain size can be directly formed from the mixture of mechanical chips made from the solidified blocks. This success stimulates the movement toward minimization of waste emission. First, pure aluminum in the grade of $1 \mathrm{xxx}$ used for electrical parts can be reused for input of this process. Second, pure silicon waste from semi-conductive fabricator can be also reused as an additive to $\mathrm{Al}-\mathrm{Si}$ alloys in BMA. Morphology-free processing is favored for broadening the silicon selection: wafers, rods, powders, blocks or granules can be accepted as a silicon source for this alloy. Robustness to iron contaminants can also afford to broaden the material selection for aluminum. This wide material selection completely reduces TMR for input materials to processing and links a new relation among different industries with a new material flow.

Except for the final sinter-forging to make net-shaping to automotive parts, every process in the solid-state recycling can be performed in green or with adaptive manner to greenforming style. Through further demonstration, this innovation in recycling technologies must grow to a standard for solid state recycling with in-process improvement of mechanical properties.

\section{Acknowledgements}

Intimate discussion with members of the research committee on the Barrier-Free Processing was helpful to promote the present study. This work was financially supported by the National Project on "Barrier-Free Processing of Materials for Life-Cycle Design for Environment (Barrier-Free Processing for DfE)" from STA (Science and Technology Agency), Japan.

\section{REFERENCES}

1) Handbook of Environmental Conscious Materials, (McGraw Hill, 2001) (in press).

2) M. Mabuchi, K. Halada and T. Aizawa: Mater. Trans. 43 (2002) 285291.

3) T. Murata: Private Communication (2001).

4) K. Halada: Key Note Speech of JIM Symposium. (2001, Sep.).

5) T. Aizawa, K. Tatsuzawa and J. Kihara: J. Faculty of Engineering, University of Tokyo. XLII (1993) 261-279.

6) O. Kobayashi, T. Aizawa and J. Kihara: Mater. Trans., JIM 37 (1996) 1497-1504.

7) T. Aizawa, J. Kihara and D. J. Benson: Mater. Trans., JIM 36 (1995) 138-149.

8) T. Aizawa, T. Luangvaranunt and K. Kondoh: Proc. ECOMATERIALS, (Metallurgical Society of Canada, 2000, Ottawa) 273-288.

9) T. Aizawa, T. Luangvaranunt and K. Kondoh: J. Japan Inst. Metals 65 (2001) 581-588.

10) K. Kondoh, T. Luangvaranunt and T. Aizawa: Mater. Trans., 42 (2001) 1254-1257.

11) X. P. Niu, L. Froyen, L. Delaey: J. Mater. Sci., 29 (1994) 3724-3732.

12) J. C. Ehrstrom: Mater. Sci. Eng. A. 186 (1994) 55-64.

13) D. K. Mukhopadhyay, C. Suryanarayana and F. H. Froes: Scr. Metall. Mater. 31 (1994) 333-338.

14) D. K. Mukhopadhyay, C. Suryanarayana and F. H. Froes: Metall. Mater. Trans. A 26 (1995) 1939-1946.

15) V. I. Fadeeva and A. V. Leonov: Mater. Sci. Eng. A A206 (1996) 90-94.

16) B. Huang, K. N. Ishihara and P. H. Shingu: Mater. Sci. Eng. A A231 (1997) 72-79.

17) O. N. Senkov and F. H. Froes: Nanostruc. Mat. 10 (1998) 691-698. 